\title{
Inhibition of aortic histamine synthesis by $\alpha$-hydrazinohistidine inhibits increased aortic albumin accumulation in experimental diabetes in the rat
}

\author{
T. M. Hollis and S.A. Strickberger \\ Department of Biology, Mueller Laboratory, The Pennsylvania State University, University Park, USA
}

\begin{abstract}
Summary. We examined the interrelationship between inhibition of aortic histamine synthesis through inhibition of aortic histidine decarboxylase and intra-aortic albumin accumulation in rats made diabetic by a jugular vein injection of $60 \mathrm{mg} / \mathrm{kg}$ of streptozotocin under ether anesthesia. Animals were held for 4 weeks following overt manifestation of diabetes. At the end of 3 weeks, at least six animals in each of the diabetic and non-diabetic groups received intra-peritoneal injections of $\alpha$-hydrazinohistidine ( $25 \mathrm{mg} / \mathrm{kg}$ at $12 \mathrm{~h}$ ) for the last 7 days. Aortic albumin accumulation was measured by quantification of aortic uptake of fluorescein isothiocyanate conjugated to rat serum albumin injected in the jugular vein $1 \mathrm{~h}$ before sacrifice. The aortic albumin mass transfer and flux rates of the diabetic group were more than $300 \%$ higher than that of the control group; $\alpha$-hydrazinohistidine treated dia-
\end{abstract}

betic rats had aortic albumin mass transfer rates equivalent to control values. The aortic albumin content was nearly tenfold higher in untreated diabetic rats, but again treatment with $\alpha$ hydrazinohistidine returned this to control values. These data offer strong support to the premise that accelerated aortic histamine synthesis, which occurs in experimental diabetes, is an important mediator of increased aortic macromolecule uptake, and as such, may be one component of the multitude of factors responsible for increased susceptibility of atherosclerosis among individuals having diabetes mellitus.

Key words: Diabetes, histamine synthesis, aortic albumin accumulation, aortic permeability, atherosclerosis, atherogenesis.

tracellular histamine content of both cell types is increased proportionately [7]. Furthermore, we have shown that in cholesterol-induced atherosclerosis in rabbits, partial inhibition of the increased aortic histamine synthesis by $\alpha$-hydrazinohistidine $(\alpha-\mathrm{HH})$ produces a $51 \%$ decrease in aortic albumin accumulation and a $63 \%$ decrease in the severity of atherosclerosis [8]. Most recently, we have shown that $\alpha$-HH prevents the increase in the aortic endothelial and smooth muscle cell histamine content in experimental diabetes, despite the persistence of severe diabetes [9]. The present study was designed to determine whether the increased aortic albumin accumulation occurring in diabetes can be prevented by the administration of $\alpha-\mathrm{HH}$, a relatively specific inhibitor of histidine decarboxylase $[10,11]$.

\section{Materials and methods}

\section{Animals}

Male Wistar rats with initial body weights of $200-230 \mathrm{~g}$ were used in this study. Animals were divided into four treatment groups with at least six animals $(n=6)$ per group. The treatment groups consisted of thelial and smooth muscle histamine synthesis are increased, histamine catabolism is decreased, and the in- 

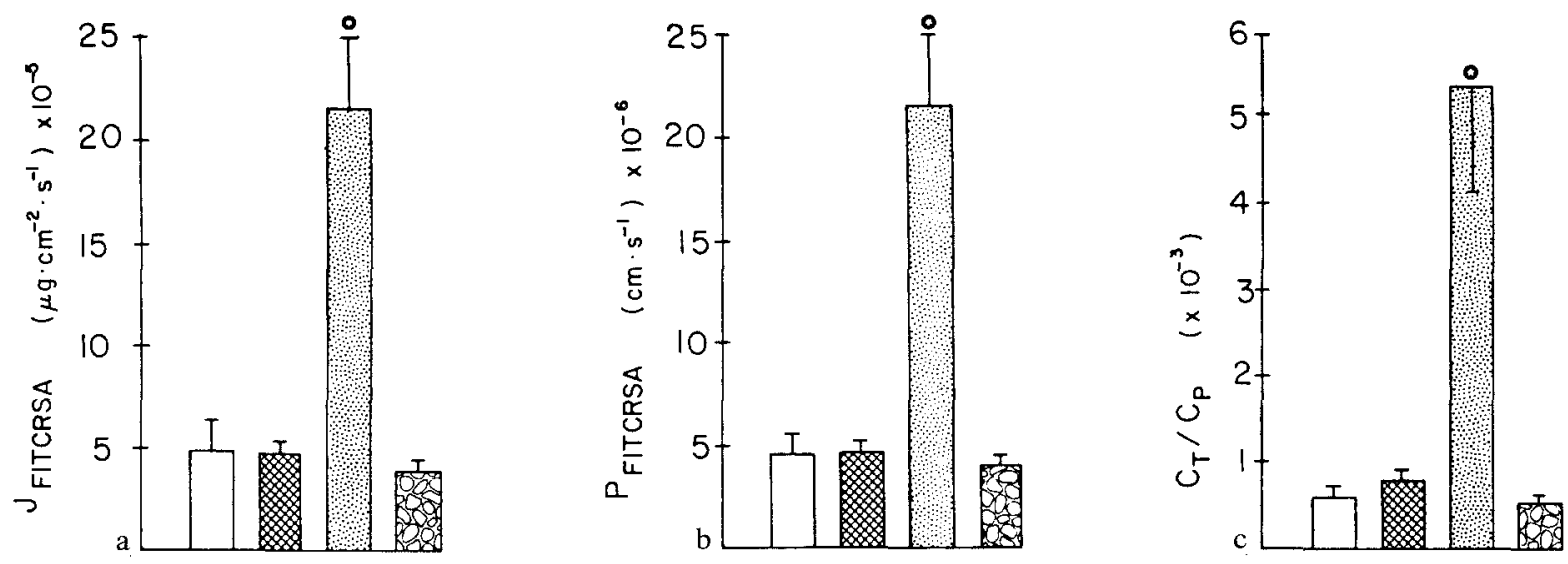

Fig. 1 a-c. Rat thoracic aortic fluorescein isothiocyanate conjugated to rat serum albumin (FITCRSA) flux and mass transfer rates, and aortic FITCRSA content in experimental diabetes. a FITCRSA flux $\left(J, \mu \mathrm{g} / \mathrm{cm}^{2} / \mathrm{s}\right) ; \mathbf{b}$ corresponding FITCRSA mass transfer rate $(P, \mathrm{~cm} / \mathrm{s}) ; \mathbf{c}$ aortic/ plasma FITCRSA ratios $\left(\mathrm{C}_{\mathrm{T}} / \mathrm{C}_{\mathrm{P}}\right)$ of each treatment group. $\alpha$-HH is $\alpha$-hydrazinohistidine given by intraperitoneal injection $(50 \mathrm{mg} / \mathrm{kg}$ at $12 \mathrm{~h})$ during week $4 .{ }^{*} p<0.05$ difference from control (variance analysis followed Duncan's multiple range test)

untreated animals (controls, $n=7$ ), non-diabetic animals receiving $\alpha$ HH $(n=7)$, diabetic animals $(n=9)$, and diabetic animals receiving $\alpha-\mathrm{HH}(n=6)$.

Diabetes was induced under light anaesthesia by jugular vein injection of streptozotocin (Sigma Chemicals, St. Louis, Missouri, $60 \mathrm{mg} / \mathrm{kg}$ in acid saline, $0.5 \mathrm{ml}, \mathrm{pH} 4.5$ ), followed by an intra-peritoneal injection of glucose $(1.75 \mathrm{~g} / \mathrm{kg}, 40 \%$ solution $)$. All control animals were weight-mateched and received a sham injection of acid saline only. All animals were fed Purina Rat Chow (Ralston Purina, St. Louis, Missouri) and water ad libitum. Three days after streptozotocin injection, non-fasting plasma and urinary glucose concentrations were measured using a glucose analyzer (Yellow Springs Instruments, Cleveland, Ohio). Animals were declared diabetic if their plasma and urinary glucose concentrations exceeded $13.7 \mathrm{mmol} / \mathrm{l}$ and $8.9 \mathrm{mmol} /$ 1, respectively. Additional non-fasting plasma and urinary glucose concentrations were determined 2 and 4 weeks after diagnosis. During week 4 , some animals in each group received $\alpha$-HH (Regis Chemicals, Morton Grove, Illinois, $25 \mathrm{mg} / \mathrm{kg}$, intraperitoneally at $12 \mathrm{~h}$ ).

\section{Measurement of aortic albumin accumulation}

At the end of the 4-week period, rats were injected with fluorescein isothiocyanate (FITC, Sigma) conjugated to rat serum albumin (Sig$\mathrm{ma}$ ). The dose was $50 \mathrm{mg} / \mathrm{kg}$ in $1 \mathrm{ml}$ of carbonate-bicarbonate buffer (pH 7.4). Plasma samples were obtained at 3 and $60 \mathrm{~min}$ after injection for subsequent determination of the plasma FITC-albumin concentration. At $60 \mathrm{~min}$ after FITC-albumin injection, animals were killed by decapitation under ether anaesthesia. The aorta was perfused with ice-cold phosphate-buffered saline (PBS, $0.01 \mathrm{~mol} / 1$, $\mathrm{pH}$ 7.4), and the aortic length was measured from the aortic arch to the diaphragm. The aorta was quickly excised, cleaned of adhering blood and the periadventitia, weighed, cut longitudinally, stretched to its original length in vivo, and traced for surface area determinations. A $10 \%$ homogenate was then prepared in ice-cold PBS $(0.01 \mathrm{~mol} / 1, \mathrm{pH} 7.4)$, and the supernatant was decanted and used to quantify the aortic FITC-albumin content.

The fluorescein isothiocyanate was conjugated to rat serum albu$\mathrm{min}$ using the procedure of Katora and Hollis [12]. Briefly, $3 \mathrm{mg}$ of fluorescein isothiocyanate were dissolved in a minimum volume of acetone and added to a solution of $50 \mathrm{mg}$ of rat serum albumin $/ \mathrm{ml}$ of carbonate-bicarbonate buffer ( $\mathrm{pH} 9.0$ ). The solution was stirred for $24 \mathrm{~h}$ $\left(4^{\circ} \mathrm{C}\right.$ ). The resulting fluorescein isothiocyanate-rat serum albumin conjugate was purified by means of gel filtration, using Sephadex G25 (Pharmacia, Piscataway, New Jersey). The $\mathrm{pH}$ was adjusted to 7.4 using $5 \mathrm{~N} \mathrm{HCl}$, and the final protein concentration was determined by the method of Lowry et al. [13].
Purity of the fluorescein-albumin solution was determined by adding $0.1 \mathrm{ml}$ of the albumin solution to each of two $15-\mathrm{ml}$ Corex tubes (Corning, Corning, New York), one containing $4.9 \mathrm{ml}$ of trichloroacetic acid and the other $4.9 \mathrm{ml}$ distilled water. After centrifugation at $20000 \times g$ for $20 \mathrm{~min}$ to remove precipitated protein, a $0.5-\mathrm{ml}$ aliquot of supernatant was placed in a microcuvette (Beckman, Irvine, California), and the fluorescence was measured with a spectrofluorometer (Perkin Elmer model MPF-43 A, New York, New York) at wavelengths of $410 \mathrm{~nm}$ excitation and 580 emission. The ratio of superpernatant fluorescence following trichloroacetic acid precipitation to that of the fluorescein-albumin conjugate was $0.1 \%$; by this criterion the fluorescein-albumin conjugate was considered devoid of any significant amount of unreacted fluorescein isothiocyanate [12].

Both aortic supernatant and plasma fluorescein-albumin concentrations were determined as follows. A $0.5-\mathrm{ml}$ aliquot was transferred to a microcuvette, and the percentage fluorescence was measured using the wavelengths listed above. These values were compared with those obtained from a standard curve and corrected for dilution. Background fluorescence in each case was below the limits of assay sensitivity which is $1 \mathrm{ng} / \mathrm{ml}$.

Three different parameters were used to measure thoracic aortic albumin accumulation. Albumin flux was calculated using the equation:

$\mathrm{J}=(\mathrm{C})(\mathrm{A})^{-1}(\mathrm{t})^{-1}$,

where $\mathrm{J}=$ albumin flux $\left[(\mathrm{mg})\left(\mathrm{s}^{-1}\right)\left(\mathrm{cm}^{-2}\right)\right], \mathrm{C}$ is the aortic fluoresceinalbumin content (mg), A is the aortic surface area $\left(\mathrm{cm}^{2}\right)$, and $\mathrm{t}$ is the circulation time $(3600 \mathrm{~s})$. The plasma fluorescein-albumin concentration $(\mathrm{mM} / \mathrm{l}) 60 \mathrm{~min}$ following injection of the fluorescein-albumin conjugate $\left(C_{P} 60\right)$ was determined directly from the standard curve. The mass transfer rate $(P, \mathrm{~cm} / \mathrm{s})$ was then obtained by the equation:

$\mathrm{P}=\left[(\mathrm{J})\left(\mathrm{C}_{\mathrm{P}} 60^{-1}\right)\right]$.

In addition, to measure aortic fluorescein-albumin accumulation aortic/plasma fluorescein-albumin ratios were determined by dividing the aortic albumin content $\left(\mathrm{C}_{\mathrm{t}}, \mathrm{mg}\right.$ fluorescein-albumin $/ \mathrm{mg}$ aorta) by $C_{P} 60$ ), thereby normalizing the individual aortic fluorescein-albumin contents to the respective plasma fluorescein-albumin contents.

\section{Statistical evaluations}

Data were analyzed initially by variance analysis. When appropriate, differences were tested for significance using the Duncan's multiple range test [14]. Differences were considered significant at the $95 \% \mathrm{lev}$ el of confidence $(p<0.05)$. 


\section{Results}

All streptozotocin-treated rats showed hyperglycaemia (30 mmol/1 vs $6 \mathrm{mM} / \mathrm{L}$ for control animals) and glycosuria $(>8.9 \mathrm{mmol} / \mathrm{l})$. Within the control and streptozotocin groups, $\alpha-\mathrm{HH}$ treatment during week 4 failed to produce any significant changes in either of these metabolic parameters. All streptozotocin-treated rats exhibited reduced weight gain over the 4 week period, typical of similar results reported previously [7].

The thoracic aortic albumin flux in the diabetic group was $300 \%$ greather than that of the control group (Figure $1 \mathrm{a}, p<0.05$ ). Aortas from diabetic rats given $\alpha$ HH showed an $83 \%$ reduction in the albumin flux when compared with the uncontrolled diabetic group $(p<$ 0.05 ). The mean albumin flux rate of the diabetic $\alpha-\mathrm{HH}$ group was not significantly different from that of the control group or the non-diabetic group receiving $\alpha$ $\mathrm{HH}$.

The aortic albumin mass transfer rate from animals of the diabetic group was elevated in excess of $300 \%$ over that of the control group (Fig. 1b, $p<0.05$ ). Again, $\alpha-\mathrm{HH}$ treatment of these diabetic animals produced a complete reversal in this parameter, the mass transfer rate now being the same as that of the control. There were no significant differences between mass transfer rates of control animals, non-diabetic $\alpha-\mathrm{HH}$, and diabetic $\alpha$-HH-treated animals.

The aortic/plasma albumin ratios of the various treatment groups are shown in Figure $1 \mathrm{c}$. As indicated, the $C_{t} / C_{p} 60$ ratio from aortas of diabetic animals was increased 10 times over control values. However, in the group of diabetic rats treated with $\alpha-\mathrm{HH}$, the $\mathrm{C}_{\mathrm{t}} / \mathrm{C}_{\mathrm{p}} 60$ ratio was reduced by $91 \%$ over that of the untreated diabetic animals $(p<0.05)$. There were no significant differences in the $C_{t} / C_{p} 60$ ratios between controls and either the non-diabetic, $\alpha$-HH-treated, and diabetic, $\alpha$ $\mathrm{HH}$-treated animals.

\section{Discussion}

Bratzler et al. [15] examined the I-albumin mass transfer rate in the descending thoracic aorta of normal rabbits. They reported a mass transfer rate of $2.4 \times 10^{-8} \mathrm{~cm} / \mathrm{s}$ following $30 \mathrm{~min}$ of $\mathrm{I}$-albumin circulation. Owens and Hollis [16], using a fluorescein-bovine serum albumin conjugate and a circulation time of $60 \mathrm{~min}$, observed a mean mass transfer rate of $1.28 \times 10^{-6} \mathrm{~cm} / \mathrm{s}$ in Evans blue dye-positive regions of normal canine aorta. Using the same fluorescein-albumin conjugate in diabetic rats Hollis et al. [17] have reported that the aortic albumin mass transfer rate changes from $6 \times 10^{-6}$ to $3.5 \times 10^{-6}$ $\mathrm{cm} / \mathrm{s}$ over a $60-\mathrm{min}$ period. Considering the differences in animal species used and differences in measurement techniques, the values in the present study are in basic agreement with those of these previous studies [15-17].
The data of this study clearly show that aortas from untreated diabetic rats had a mass transfer rate which was more than $300 \%$ greater than control animals. Furthermore, the albumin flux rate was $325 \%$ greater than in control animals. Consistent with these observations is the fact that there is a tenfold increase in the aortic fluorescein-albumin content in these diabetic rats when it is normalized to the plasma fluorescein-albumin content on a per weight basis. Thus, these data show that there is a significantly greater macromolecule accumulation in aortas from these diabetic rats, an accumulation caused by lowered endothelial resistance which creates an increase in aortic wall permeability characteristics. The result of this increased permeability is that increased quantities of albumin enter the aortic wall per unit area of vessel.

The most significant aspect of this study is the finding that with $\alpha-\mathrm{HH}$ treatment, a relatively specific inhibitor of histidine decarboxylase $[10,11]$ which is the principle enzyme catalyzing the formation of histamine, the aortic albumin uptake is returned to control values. This is shown by a reduced albumin flux, a reduced mass transfer rate, and it is reflected by the normalized tissue/plasma ratio of the fluorescein-albumin. Moreover, this occurs despite severe hyperglycaemia and hypoinsulinemia. Thus, in this study altered permeability characteristics of the vessel wall have been dissociated from both hyperglycaemia and hypoinsulinemia of diabetes mellitus simply by inhibiting increases in aortic histamine synthesis [9].

The mode of action of $\alpha-\mathrm{HH}$ is still unsolved. One mechanism of action of $\alpha-\mathrm{HH}$ is to bind pyridoxial phosphate $[10,11]$ which is a necessary cofactor for histidine decarboxylase. However, Levine et al. [11] have shown that $\alpha-\mathrm{HH}$ is 10 times more effective in inhibiting histidine decarboxylase than in inhibiting aromatic L-amino acid decarboxylase, an enzyyme which is also pyridoxal phosphate-dependent [19]. Thus, it is presumed that $\alpha-\mathrm{HH}$ in some manner prevents binding of pyridoxal phosphate with the histidine decarboxylase molecule, although how this occurs is still obscure.

It has been our working hypothesis that increased aortic macromolecule accumulation occurring in various atherogenic states is mediated, at least in part, by accelerated de novo histamine synthesis catalyzed by increased histidine decarboxylase activity. Orlidge and Hollis [7], in their studies of aortic histamine metabolism in experimental diabetes, showed that the intracellular histamine content of both endothelial and smooth muscle cells underwent a marked expansion in experimental diabetes. Importantly, this expansion could be completely reversed by insulin therapy during the last week of the 4-week period. Similarly, Gallik et al. [9] showed recently that in diabetic animals treated with $\alpha$ $\mathrm{HH}$ the expansion in intracellular histamine was likewise completely blocked, despite the persistence of severe diabetes. This indicates that the inducible nonmast cell histamine pool, a pool which is dependent up- 
on the rate of histamine synthesis and catabolism [10, 11], is sensitive to insulin, and that one significant change occurring in experimental diabetes is an expansion of this inducible pool. Whether these changes reflect hypoinsulinemia or hyperglycaemia or both cannot be stated at this time.

A natural question which arises from this study is the question of how histamine would mediate abnormal aortic permeability increases to macromolecules such as albumin. We have no definitive data at this time. However, in a related study Hollis et al. [20] have reported that plasma histamine concentrations are markedly elevated in streptozotocin-diabetic rats. Furthermore, this elevated plasma histamine concentration can be minimized by treatment with $\alpha-\mathrm{HH}$, suggesting that a major component responsible for the altered plasma histamine concentration is an expanded inducible histamine pool. Thus, one possible mechanism through which histamine might mediate such changes could be through interaction with histamine $\mathrm{H}_{1}$ - and/or histamine $\mathrm{H}_{2}$ receptors, thereby stimulating endothelial pinocytosis and the transendothelial transport of macromolecules such as albumin. Obviously this needs to be investigated in detail, and such studies are currently in progress in this laboratory.

The data of the present study indicate that if this inducible histamine pool expansion can be prevented, then increases in aortic permeability characteristics such as aortic albumin flux and mass transfer rates can likewise be prevented. The effect of this prevention is to block abnormal aortic albumin accumulation, even in spite of severe hyperglycaemia and hypoinsulinemia. These data also indicate that fluorescein conjugated molecules serve as excellent and sensitive probes for measuring various permeabiity parameters in large vessels; fluorescein has been used for some time in assessing retinal-blood barrier properties in human diabetes [21]. Taken together, these data thus give strong support for the concept that accelerated de novo histamine synthesis is at least one important event occurring in experimental diabetes which is intimately associated with certain increased vascular wall permeability characteristics associated with both diabetes and atherogenesis.

Acknowledgments. Supported by a grant from the Coronary Heart Disease Research Project, a program of the American Health Assistance Foundation.

\section{References}

1. Brownlee M, Cahill GF (1979) Diabetic control and vascular complications. In: Paoletti RW, Gotto AM (eds) Atherosclerosis reviews, Vol.4. Raven Pres, New York, pp 29-70
2. Jarrett RJ, Keen H (1975) Diabetes and atherosclerosis. In: Keen H, Jarrett RJ (eds) Complications of diabetes. Edward Arnold, London, pp 179-205

3. Mitchell J, Schwartz C (1965) Arterial disease. Blackwell, Oxford

4. Robertson WB, Strong JP (1968) Atherosclerosis in persons with hypertension and diabetes mellitus. Lab Invest 18: 538-551

5. Gordon T, Castelli WP, Hjortland MC, Kannel WB, Dawber TR (1977) Predicting coronary heart disease in middle-aged and older persons. The Framingham study. JAMA 238: 497-499

6. Stout RW (1979) Diabetes and atherosclerosis: the role of insulin. Diabetologia 16: 141-150

7. Orlidge A, Hollis TM (1982) Aortic endothelial and smooth muscle histamine metabolism in experimental diabetes. Arteriosclerosis $2: 142-150$

8. Owens GK, Hollis TM (1979) Relationship between inhibition of aortic histamine formation, aortic albumin permeability and atherosclerosis. Arteriosclerosis 34: 365-373

9. Gallik SG, Orlidge A, Yost J, Hollis TM (1981) Aortic endothelial and smooth muscle histamine pools in streptozotocininduced diabetes. Fed Proc 40: 328 (Abstract)

40. Levine RJ, Noll WW (1969) Histidine decarboxylase and its inhibition. Ann NY Acad Sci 166: 246-256

11. Levine RJ, Sato TL, Sjoerdsma A (1965) Inhibition of histamine synthesis in the rat by alpha-hydrazine analog of histidine and 4-bromo-3-hydroxy-benzoxyamine. Biochem Pharmacol 15: 841-849

12. Katora ME, Hollis TM (1975) A simple fluorescent method for determination of aortic protein uptake. A Appl Physiol 29: 145-149

13. Lowry OH, Rosebrough NJ, Farr AL, Randall RJ (1954) Protein measurement with the folin phenol reagent. J Biol Chem 193: 265-275

14. Snedecor GW, Cochran WG (1980) Statistical methods, 4th edn. Iowa State University Press, Ames

15. Bratzler RL, Chisolm GM, Colton CK, Smith KA, Zilversmit DB, Lees RS (1977) The distribution of labeled albumin across the rabbit thoracic aorta in vivo. Circulation Res 40: 182-190

16. Owens GK, Hollis TM (1981) Local aortic histamine metabolism and albumin accumulation: Difference between blue and white areas. Arteriosclerosis 1: 265-272

17. Hollis TM, Enea NA, Kern JA (1984) Time-dependent changes in aortic permeability characteristics in experimental diabetes. Exp Mol Pathol 207-217

18. Hakenson R (1963) Histidone decarboxylase in the fetal rat. Biochem Pharmacol 12: 1289-1296

19. Lovenberg W, Barchas J, Weissbach H, Undenfriend S (1963) Characteristics of the inhibition of aromatic L-amino acid decarboxylase by $\alpha$-methylamino acids. Arch Pharmacol 12: 1289-1299

20. Hollis TM, Kern JA, Enea NA, Cosgarea AJ (1985) Changes in plasma histamine concentration in the streptozotocin-diabetic rat. Exp Mol Pathol (in press)

21. Zeimer RC, Cunha-Vaz JH, Johnson ME (1982) Studies on the technique of vitreous fluorophotometry. Invest Ophthalmol Vis Sci 22: 668-674

Received: and in revised form:

Dr. Theodore M. Hollis 208 Mueller Laboratory The Pennsylvania State University University Park, PA 16802

USA 